XVII COLÓQUIO INTERNACIONAL DE GESTÃO UNIVERSITÁRIA
Universidade, desenvolvimento e futuro na Sociedade do Conhecimento
Mar del Plata - Argentina
22,23 e 24 de novembro de 2017
ISBN: $978-85-68618-03-5$

\title{
APRENDIZAGEM E MUDANCCA PARA A SUSTENTABILIDADE: ESTUDO EM UMA INSTITUIÇÃO DE ENSINO SUPERIOR BRASILEIRA
}

\author{
GABRIELA ALMEIDA MARCON \\ Universidade Federal de Santa Catarina \\ gabriela@almeidamarcon.com \\ FERNANDA ALMEIDA MARCON \\ Universidade Federal de Santa Catarina \\ fernanda@almeidamarcon.com \\ RUDIMAR ANTUNES DA ROCHA, Ph.D. \\ Universidade Federal de Santa Catarina \\ rrudimar@hotmail.com
}

\section{RESUMO:}

As instituições de ensino superior, como organizações intensivas em conhecimento, possuem papel fundamental na conscientização sobre questões socioambientais, pois formam as novas lideranças. Diante deste quadro, pretende-se responder: Que mudanças organizacionais devem ser implementadas em uma instituição de ensino superior ante as preocupações com a sustentabilidade? Este estudo analisa a aprendizagem organizacional com ênfase no processo de aprendizagem e considera a universidade como sendo uma organização de aprendizagem. A abordagem é qualitativa. Utilizou-se entrevistas semiestruturadas e observação participante a fim de coletar dados para análise. O objetivo final foi atingido, sendo possível sintetizar propostas de melhoria pelos entrevistados em quatro temáticas principais, a saber: mobilidade urbana, pesquisa, extensão e processos internos da universidade. Como limitações do estudo, tem-se o pouco tempo disponível dos entrevistados para retomada dos tópicos questionados. Recomenda-se que, em pesquisas futuras, seja analisada a aprendizagem como foco na sugestão de um modelo de processo de aprendizagem organizacional para a Universidade Federal de Santa Catarina.

Palavras-chave: Sustentabilidade, mudanças organizacionais, aprendizagem organizacional, instituições de ensino superior, estudo de caso. 


\section{INTRODUÇ̃̃̃O}

As preocupações com o meio ambiente têm conduzido mudanças organizacionais na sociedade atual. As instituições de ensino superior, como organizações intensivas em conhecimento, possuem papel fundamental nestas transformações, pois formam as novas lideranças.

A educação vem sendo descrita em relatórios internacionais como uma das ferramentas mais poderosas para formar indivíduos com as habilidades, competências e atitudes imprescindíveis para a formação de cidadãos e consumidores sustentáveis (OECD, 2008). O debate emergente sobre a educação para o desenvolvimento sustentável é reflexo das crescentes dúvidas acerca do papel das instituições de ensino superior (ADOMßENT et al., 2014).

A expectativa de que as instituições de ensino superior sejam líderes de pensamento e ação sobre questões relacionadas com a responsabilidade social corporativa e a sustentabilidade foi reforçada em virtude de diversos fatores críticos associados à formação de gestores conscientes (GODEMANN et al., 2014).

Apesar do crescente número de programas voltados à sustentabilidade ter surgido nos últimos anos, constatações empíricas apontam que as exigências profissionais e os métodos eficazes para educação de agentes de mudança ainda são limitados (HESSELBARTH; SCHALTEGGER, 2014).

O consumo e desenvolvimento sustentáveis são tópicos importantes, mas ainda marginalizados no ensino superior (BARTH et al., 2014). Assim, há grande oportunidade de pesquisa nesta área. $\mathrm{O}$ estudo acerca da percepção dos acadêmicos sobre mudanças e aprendizagem organizacional para a sustentabilidade representa significativa contribuição para a comunidade científica.

Há, hodiernamente, exemplos de instituições de ensino superior em busca da redução de seus vestígios de degradação ambiental por meio de programas de ecologização do campus, iniciativas muitas vezes lideradas por estudantes e pesquisadores (WALS, 2014; UFSC, 2013). As compras públicas no Brasil representam aproximadamente dez por cento do PIB nacional (BIDERMAN et al., 2006), sendo as Universidades Federais grandes consumidoras.

Diante deste quadro, pretende-se responder, na perspectiva dos usuários estudantes: Que mudanças organizacionais devem ser implementadas em uma instituição de ensino superior ante as preocupações com a sustentabilidade?

Este estudo analisa a abordagem da aprendizagem organizacional com ênfase no processo de aprendizagem e considera a universidade como sendo uma organização de aprendizagem na definição de Senge (1990). Ainda, considera-se que a implantação de mudanças organizacionais demanda um processo de aprendizagem.

Buscou-se analisar a influência das demandas da sustentabilidade nas mudanças operadas em uma instituição de ensino superior a partir da visão de seus usuários estudantes.

Para tanto, objetivou-se, especificamente, examinar o que seria uma instituição de ensino superior sustentável na perspectiva dos usuários estudantes e que mudanças, em sua concepção, deveriam ser implementadas pela instituição em termos de processos internos, entre outros aspectos gerenciais.

Ainda, o estudo buscou identificar a compreensão dos estudantes acerca de projetos já implementados pela instituição a que estão vinculados. A sugestão de modelos de aprendizagem organizacional para a sustentabilidade não é objeto deste estudo.

\section{APRENDIZAGEM ORGANIZACIONAL PARA UMA UNIVERSIDADE SUSTENTÁVEL}


É comum a percepção de que uma organização progride às custas da comunidade ao seu redor (PORTER; KRAMER, 2011). As organizações empresariais atingiram o ponto em que ou incluem o ambiente natural como uma de suas preocupações estratégicas, ou serão responsabilizadas pelos stakeholders pelos problemas ambientais (SANDHU, 2010; DICLE; KOSE, 2014), o mesmo vem sendo exigido de instituições públicas e sem fins lucrativos.

A perspectiva da preservação ambiental como fator limitador das potencialidades econômicas moldou as estratégias das organizações em décadas passadas, mas este paradigma precisa ser repensado (PORTER; KRAMER, 2011).

Os impactos socioambientais das organizações devem ser preocupação recorrente das universidades, sobretudo, ante a função educacional, crítica e humanitária que exercem na comunidade em que estão inseridas (NICOLAIDES, 2006; SHRIBERG, 2002; MOORE, 2005; GODEMANN et al., 2014). As universidades possuem, destarte, papel chave na promoção do desenvolvimento sustentável (AMARAL; MARTINS; GOUVEIA, 2015). Neste norte, a aprendizagem organizacional para promoção da sustentabilidade em instituições de ensino superior adquire especial relevância.

A aprendizagem organizacional é uma das temáticas mais discutidas na seara da gestão (CHADWICK; RAVER, 2015). Particularmente, quatro temáticas destacam-se quanto aos estudos predominantes acerca da aprendizagem organizacional, são eles: adaptação organizacional, aprendizado a partir da experiência e modelo de feedback de desempenho (KOO et al., 2016).

O desenvolvimento da capacidade de pensamento e produtividade mediante comprometimento de aprimoramento contínuo é obtido através do processo de aprendizagem organizacional (MARQUARDT, 2002).

A abordagem da aprendizagem organizacional cuida das dimensões características do processo de aprendizagem, enquanto que o termo "organizações de aprendizagem" (SENGE, 1990) alude às dimensões ou características da organização como agente que procura ou objetiva o desenvolvimento deste processo (EASTERBY-SMITH, 1997). Para Weick e Westley (1996) os termos aprendizagem e organização seriam, a priori, antagônicos. Isto porque aprender requer desorganizar, ampliar, desconstruir para reconstruir. A organização requer um certo grau de reducionismo.

O processo de aprendizagem organizacional pode ocorrer em três níveis: individual, grupal ou organizacional propriamente dito (CASTILHO; SILVA; TURIONI, 2004). O nível organizacional diz respeito à institucionalização da aprendizagem individual e coletiva, passando a integrar a memória da organização.

Para Argyris e Schon (1978) existem três tipos de aprendizagem organizacional a merecer destaque, a saber:

Quadro 1- Tipos de Aprendizagem Organizacional

\begin{tabular}{|l|l|}
\hline $\begin{array}{l}\text { 1. Aprendizagem Monocíclica (ciclo } \\
\text { simples) }\end{array}$ & $\begin{array}{l}\text { Ocorre quando os membros da organização respondem } \\
\text { ao ambiente através da descoberta e correção de erros, } \\
\text { conforme as normas preexistentes. }\end{array}$ \\
\hline $\begin{array}{l}\text { 2. Aprendizagem de ciclo duplo } \\
\text { (bicíclica) }\end{array}$ & $\begin{array}{l}\text { Este tipo não só controla os processos existentes, mas } \\
\text { inclui a mudança de cultura, políticas, metas e } \\
\text { estratégias organizacionais. Os erros são corrigidos a } \\
\text { partir da reflexão acerca dos princípios norteadores do } \\
\text { sistema. }\end{array}$ \\
\hline 3. & $\begin{array}{l}\text { Baseia-se na mudança dos métodos e requer a reflexão } \\
\text { acerca das noções individuais. Conduz a um novo nível } \\
\text { de contemplação e criação de conhecimento. Produz } \\
\text { novos modelos mentais. }\end{array}$ \\
\hline
\end{tabular}

Fonte: Argyris e Schon (1978). 
A aprendizagem monocíclica de Argyris e Schon (1978) é chamada de adaptativa por Probst e Buchel (1997), uma vez que envolve a identificação e correção de erros de forma reativa. É a organização adaptando-se ao ambiente, mas mantendo-se fiel às normas existentes. No ciclo simples a reflexão acerca das normas seguidas é reduzida ou inexistente.

O tipo de aprendizagem de ciclo duplo ou bicíclica é chamado, simplesmente, de tipo II por Bateson (1981). Para esse autor, através da aprendizagem tipo II a organização altera sua base de competências e conhecimentos mediante a análise coletiva dos erros ou problemas identificados.

Nas universidades novos padrões de pensamentos são nutridos e aspirações coletivas são liberadas e as pessoas estão continuamente desenvolvendo suas capacidades de alcançar os resultados desejados a partir da implementação e otimização de novas práticas. Assim, é possível dizer que o processo de aprendizagem organizacional nas universidades é tricíclico, considerando a definição de deutero aprendizagem proposta por Argyris e Schon (1978). O clima organizacional nas universidades favorece a aprendizagem, razão pela qual se enquadraria no tipo tricíclica (HULT, 1998).

O capital intelectual é um instrumento para a sustentabilidade (SILVEIRA et al., 2013) e as universidades, internamente, detêm competências que lhes permitem adquirir, acessar e rever a memória organizacional, fornecendo orientações para a ação institucional (LIN, 2008). Desta forma, possuem condições para promover mudanças culturais e criação de novos modelos a partir da aprendizagem organizacional.

Conceitos equivocados de sustentabilidade dificultam sua implementação nas instituições de ensino superior (LEAL FILHO, 2011), razão pela qual é importante definir os fatores de sustentabilidade em IES. Para Richards e Gladwin (1999) a gestão para sustentabilidade requer que as organizações se encaminhem para além da eficiência ecológica. Aspectos socioambientais devem fazer parte da tomada de decisão.

Velazquez et al. (2006) definem uma Universidade sustentável como sendo uma entidade que aborda, envolve e promove, a nível regional ou a nível global, a minimização dos impactos econômicos, sociais, de saúde e ambientais gerados a partir do uso de recursos naturais ou não a fim de cumprir suas funções precípuas, como ensino, pesquisa, extensão, a fim de fomentar um estilo de vida sustentável.

Uma instituição de ensino superior sustentável é uma incubadora para futuros líderes, portanto, deve promover a divulgação de boas práticas em seu entorno, objetivando o encorajamento do uso sustentável dos recursos, descarte responsável dos resíduos, etc. (THOMPSON; GREEN, 2005; ZHANG et al., 2011).

\section{METODOLOGIA}

Diante do escopo desta pesquisa, optou-se pela abordagem qualitativa, no afã de identificar a percepção dos acadêmicos. A pesquisa qualitativa é uma forma de explorar e compreender o sentido que os indivíduos ou os grupos atribuem a um problema social ou humano (CRESWELL, 2010).

A observação participantante demanda maior tempo para a obtenção dos resultados pretendidos (TAYLOR; BOGDAN, 1998), razão pela qual não será utilizada de forma isolada, mas em conjunto com outras técnicas. A observação auxilia o pesquisador a obter provas a respeito de objetivos sobre os quais os indivíduos não têm consciência, porém que norteiam seu comportamento (LAKATOS, 1996). Por ser o pesquisador atuante no contexto pesquisado, a observação participante é importante nesta pesquisa.

A técnica predominante para a coleta de dados foi a entrevista semi-estruturada. Foram entrevistados informantes com características semelhantes e de interesse do tema da pesquisa (BONI; QUARESMA, 2005). Os entrevistados são onze universitários, dentre os 
quais alunos graduação, pós-graduação e recém formados, cujas identidades são preservadas neste estudo.

A via etnográfica pareceu a mais adequada, pois ao compartilhar do tempo com certo grupo social o pesquisador tem a oportunidade de observar comportamentos que dificilmente seriam referidos abertamente pela comunidade sob estudo (MALINOWSKI,1984).

Num primeiro momento, foi realizada uma conversa com duas servidoras do núcleo de Gestão Ambiental da Universidade Federal de Santa Catarina (UFSC), a fim de obter informações acerca das ações de sustentabilidade que a Universidade vem adotando. Apenas com uma base de conhecimento acerca das ações implementadas é que a pesquisadora passou a questionar os acadêmicos usuários da instituição.

Após a coleta de dados primários, as informações foram sistematizadas. Foi utilizada a aplicação $\operatorname{Wordle}^{\circledR}$ para elaboração de nuvens de palavras-chave a partir dos relatos dos participantes. Para integração dos dados coletados, foi utilizada pesquisa documental.

\section{RESULTADOS E DISCUSSÃO}

A UFSC foi instituída pela Lei n. 3.849/1960. No ano de 1969, adquiriu a estrutura administrativa atual com previsão normativa no Decreto n. 64.824/1969 (UFSC, 2010). O setor responsável pela promoção da sustentabilidade na instituição é a Gestão Ambiental.

A Gestão Ambiental da UFSC trabalha atualmente com oito distintos eixos temáticos de preocupação, a saber: compras e contratações sustentáveis, consumo, qualidade de vida, deslocamento, água e esgoto, energia, resíduos sólidos e o eixo geral que congrega os demais.

Figura 1 - Eixos temáticos de preocupação - Sustentabilidade na UFSC

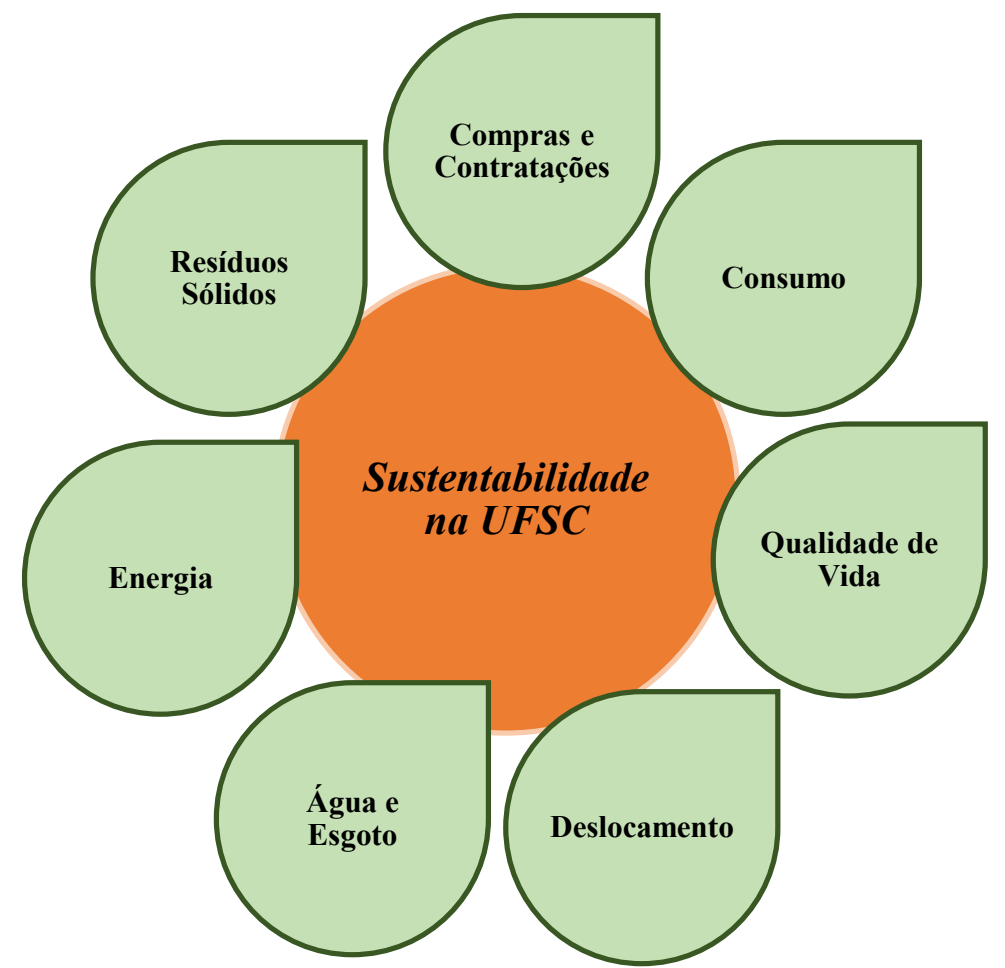

Fonte: Elaborado pela autora a partir dos dados da pesquisa (2016). 
O eixo "Compras e Contratações" busca fomentar a aquisição de materiais que observem critérios sustentáveis em sua produção. Os critérios sustentáveis passaram a ser objeto de preocupação após a alteração do Estatuto Federal de Licitações e Contratos (Lei n. 8.666/93) pela Lei Federal $n^{0} 12.349$, de 2010.

Além disto, neste mesmo eixo, a Gestão Ambiental da UFSC preocupa-se em aumentar o alcance de projetos e práticas sustentáveis no setor de compras da instituição.

Quanto ao eixo "Deslocamento", o foco da UFSC é minimizar os gastos e emissão de gases poluentes decorrentes do uso de veículos pela instituição. Uma das proposições, de acordo com a Gestão Ambiental, é aumentar o uso de transportes coletivos pela comunidade acadêmica.

O Plano de Logística Sustentável (PLS) é o documento que norteia as ações de sustentabilidade promovidas pela instituição. Em atenção ao Decreto 7.746/2012 e a Instrução Normativa $n^{\circ}$ 10/2012 do Ministério do Planejamento, Orçamento e Gestão, em 2013, a UFSC foi a primeira Universidade Federal a formalizar um PLS. No PLS 2013, a instituição trabalhava com seis eixos, pois o consumo não era uma área de preocupação autônoma e não havia o eixo geral.

Em março de 2015 foi constituída através da Portaria 322/2015, normativo interno expedido pelo Gabinete da Reitoria, a Comissão Permanente de Sustentabilidade da UFSC, a qual é composta por vinte integrantes e realiza reuniões periódicas para a discussão do PLS. O espaço instituído para discussão cria um clima organizacional que favorece a aprendizagem (HULT, 1998).

Apesar de ter sido a primeira instituição federal a formalizar seu PLS em 2013, a UFSC não logrou atualizar anualmente o plano que, de acordo com diretrizes do MEC, deveria ser revisto a cada seis meses.

A Universidade obteve diversos avanços no que diz respeito à adoção de práticas sustentáveis desde a implantação do PLS 2013. De acordo com a Gestão Ambiental, apesar dos avanços, as metas estabelecidas nos diversos eixos foram atingidas apenas parcialmente.

Para que a UFSC seja, em todos os aspectos mencionados por Velásquez et al. (2006), uma universidade sustentável, é necessário que ocorra um processo de aprendizagem tricíclico (ARGYRIS; SCHON, 1978), isto é, além de corrigir os erros e adaptar-se ao ambiente, a instituição precisa mudar seus métodos e as concepções das pessoas envolvidas nos seus processos internos. É necessário um novo modelo mental para que as práticas sustentáveis sejam ampliadas e reproduzidas.

Passou-se à análise da perspectiva dos usuários da instituição, estudantes de graduação, pós-graduação e recém-formados, acerca do que vem a ser uma instituição de ensino superior sustentável e qual seria a situação da UFSC.

Dentre os entrevistados, todos afirmaram que têm interesse por questões relacionadas ao meio ambiente e à melhoria da qualidade de vida das pessoas, reconhecendo o papel da universidade como agente de mudanças. Não houve diferenças significativas para informantes do gênero masculino ou feminino. Em geral, mostram-se insatisfeitos com a atuação das universidades em relação ao desenvolvimento sustentável. Extrai-se das entrevistas que os estudantes entendem que a instituição universitária teria o papel de conscientizar e dar exemplos de boas práticas.

Os entrevistados relataram que tomam algumas medidas em prol da preservação do meio ambiente e da diminuição de resíduos em seu dia a dia. Apenas um dos informantes manifestou conhecer um pouco acerca das ações de sustentabilidade desenvolvidas pela UFSC.

Constatou-se, ainda, que a formação superior aborda, na opinião dos usuários, timidamente a questão do consumo e produção sustentáveis, havendo pouca ou nenhuma ênfase em questões socioambientais nos currículos dos cursos. 
No que tange às ações que despontam como mais realizadas pelos estudantes em sua rotina, com a utilização da ferramenta $\operatorname{Wordle}{ }^{\circledR}$, foi composta a nuvem de palavras-chave abaixo:

Figura 2 - Ações realizadas pelos estudantes

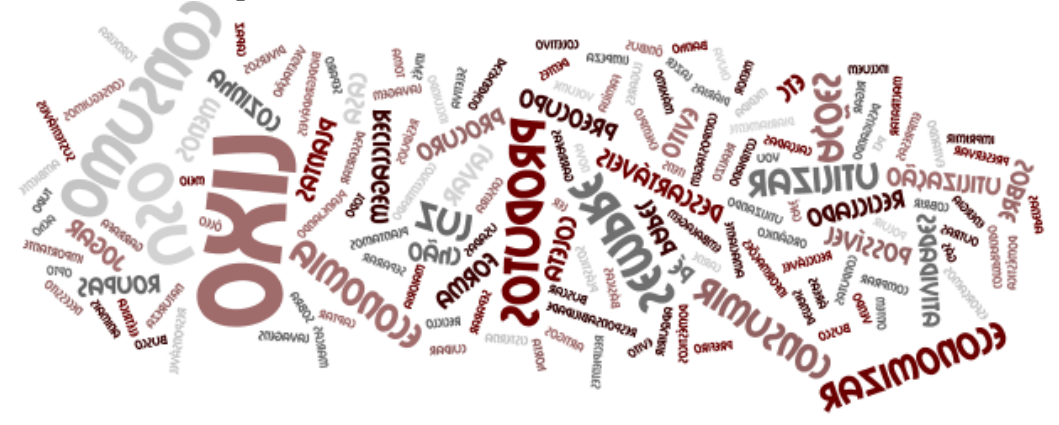

Fonte: Dados da Pesquisa (2016).

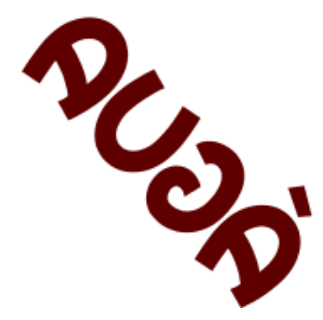

A figura acima demonstra grande preocupação dos acadêmicos com a economia de recursos, sobretudo, de água. Além disso, as palavras "lixo", "descartáveis", "reciclagem", "plantas", "consumo", "uso" e "plantas" aparecem destacadas.

Extrai-se da entrevista número nove o seguinte trecho: "Eu tento sempre consumir menos que ontem, reciclo meu lixo, vou a pé ou de ônibus para os lugares, como menos carne, vendo minha roupas usadas e uso uma garrafa de água minha ao invés de sempre comprar uma nova" (DADOS DA PESQUISA, 2016).

Vê-se que, a partir das experiências individuais dos usuários, a Universidade poderia incrementar ações de conscientização e incentivo a boas práticas em prol do meio ambiente. Em geral, verifica-se que, apesar dos esforços da Gestão Ambiental da UFSC, os acadêmicos não percebem ou não conseguem mensurar qualquer atuação da instituição no sentido de fomentar boas práticas em prol do ambiente.

Um dos informantes mencionou como boa prática ecológica da UFSC a existência de ponto de coleta para reciclagem de pilhas e baterias. Outro deles mencionou uma descarga ecológica no banheiro masculino do Centro de Eventos do campus, reutilizando água da chuva.

Os entrevistados concordam com a literatura (THOMPSON; GREEN, 2005; ZHANG et al., 2011) quando acreditam que a UFSC, na condição de formadora de opinião, deve promover projetos voltados à preservação ambiental e a conscientização da comunidade acadêmica. Acerca das ações que os informantes esperam da universidade, a aplicação Wordle ${ }^{\circledR}$ permitiu a criação da seguinte nuvem de palavras-chave: 
Figura 3 - Ações de sustentabilidade esperadas pelos usuários

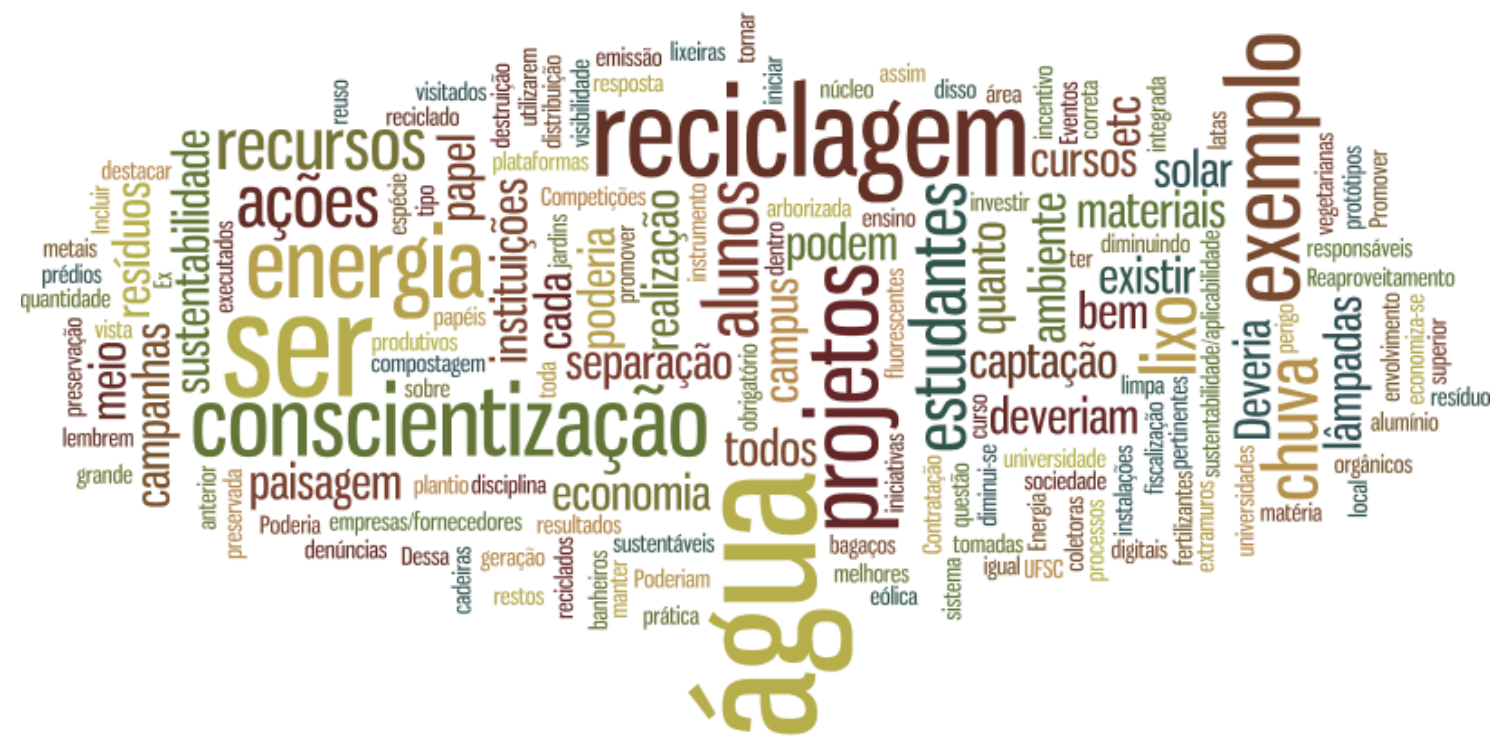

Fonte: Dados da pesquisa (2016).

Cumpre consignar que a temática da mobilidade urbana suscitou opiniões contrastantes entre os informantes. Para alguns, a cobrança do estacionamento restringiria o uso de veículos próprios, incentivando o uso do transporte público. Por sua vez, a melhoria das ciclovias e o incremento da segurança no campus incentivariam o uso de bicicletas. Os informantes identificam que não existe projeto de aluguel de bicicletas ou outro semelhante.

As principais ideias dos entrevistados acerca da mobilidade urbana atrelada ao uso do campus estão aglutinadas na nuvem de palavras abaixo:

Figura 4 - Soluções dos entrevistados para mobilidade no campus

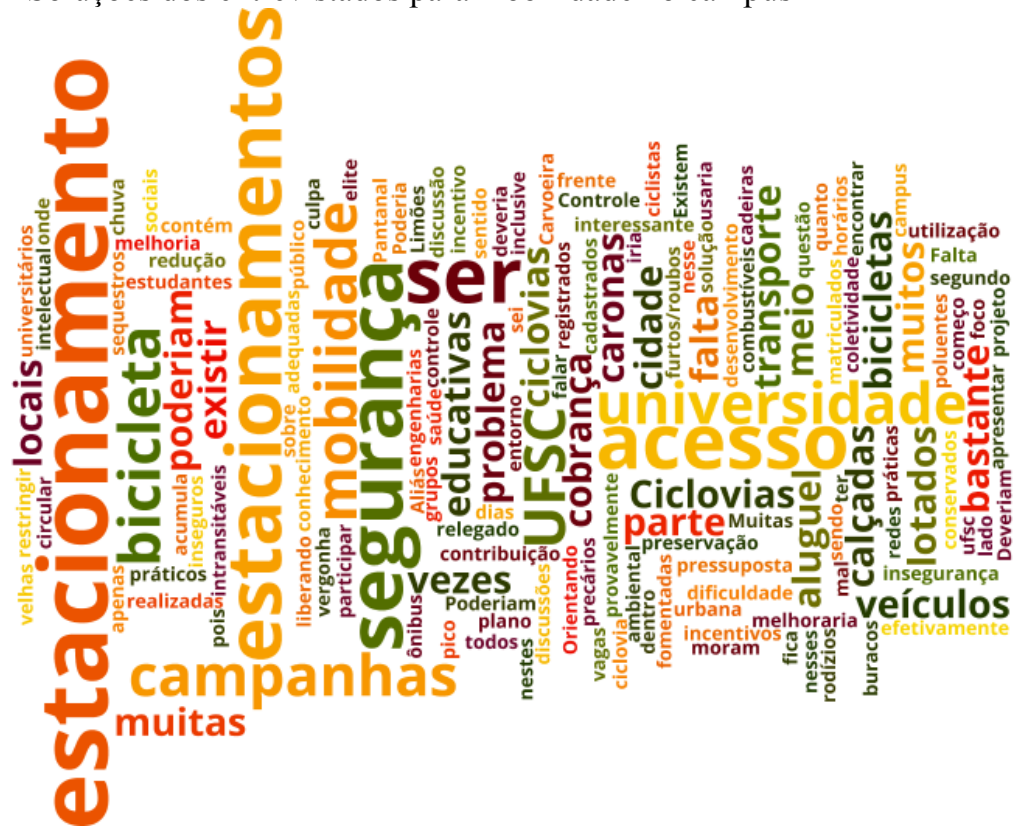


Fonte: Dados da pesquisa (2016).

As preocupações com a sustentabilidade influenciam mudanças organizacionais na medida em que a instituição é forçada a transformar seus processos internos e, antes disto, sua própria mentalidade e cultura institucional a fim de, adotando, efetivamente, práticas sustentáveis, influenciar seus usuários e o entorno.

O processo de aprendizagem organizacional não é linear e não é instantâneo, pois envolve mudança de cultura, por conseguinte, reflexão e mudança de posturas individuais.

A fim de sintetizar as mudanças organizacionais a serem objetivadas pela Universidade pesquisada, a fim minimizar os impactos econômicos, sociais, de saúde e ambientais gerados a partir do uso de recursos naturais (VELÁSQUEZ et al., 2006), na visão de seus usuários estudantes, elaborou-se o quadro abaixo:

Quadro 2 - Propostas de melhoria institucional

\begin{tabular}{|l|l|}
\hline \multicolumn{1}{|c|}{ Temática } & \multicolumn{1}{c|}{ Propostas de melhoria } \\
\hline Mobilidade Urbana & $\begin{array}{l}\text { Fomentar as alternativas ao uso do transporte } \\
\text { individual de passageiros }\end{array}$ \\
\hline Pesquisa & $\begin{array}{l}\text { A universidade, como centro de pesquisa, deve } \\
\text { buscar alternativas à produção e ao consumo } \\
\text { predatórios, manter laboratórios para isto, etc. }\end{array}$ \\
\hline Extensão & $\begin{array}{l}\text {-Criar mecanismos de fomento ao maior } \\
\text { envolvimento dos estudiosos nas discussões com } \\
\text { o Poder Público; } \\
\text {-Formar alunos e servidores conscientes; } \\
\text {-Aprimorar a divulgação de campanhas } \\
\text { comunitárias bem como seus projetos de compras } \\
\text { e consumo sustentáveis; etc. }\end{array}$ \\
\hline Processos Internos & $\begin{array}{l}\text { Deve ser, cada vez mais, reduzido o consumo de } \\
\text { recursos e a produção de resíduos, bem como } \\
\text { deve haver o descarte adequado e eficiente destes. }\end{array}$ \\
\hline
\end{tabular}

Fonte: Dados da pesquisa (2016).

Os informantes relatam que a qualidade de vida está intrinsecamente relacionada com a saúde do meio ambiente, razão pela qual, para que seja possível desfrutar do meio ambiente ecologicamente equilibrado no futuro, são necessárias transformações no modo de agir presente.

\section{CONCLUSÃO}

As universidades, como centros de formação de profissionais e opiniões, agentes de transformação social, precisam engajar-se em questões socioambientais. A mudança organizacional pode ser obtida através de um processo recursivo de aprendizagem.

Os processos de aprendizagem organizacional para sustentabilidade em instituições de ensino superior enquadrar-se-iam no tipo deutero aprendizagem. Isto porque envolvem três ciclos de aprimoramento e mudanças organizacionais.

Este estudo buscou identificar quais as mudanças organizacionais deveriam ser implementadas por uma instituição de ensino superior rumo à sustentabilidade, na perspectiva dos usuários estudantes. Tem-se que a questão de pesquisa foi respondida, uma vez que os informantes propuseram mudanças a serem implementadas em prol de melhores práticas.

Na Universidade Federal de Santa Catarina o setor de Gestão Ambiental, incentivado por normativos federais e diretrizes do Ministério da Educação, tem implementado mudanças e fomentado práticas mais sustentáveis. Os acadêmicos usuários da estrutura da UFSC, porém, ainda não conseguem perceber estas mudanças organizacionais. 
Compreendem, porém, a universidade como um agente de transformação social e acreditam que deve promover exemplos de boas práticas.

As preocupações com a sustentabilidade fomentam a aprendizagem organizacional uma vez que induzem um esforço legítimo da instituição no intuito de modificar suas práticas e sua mentalidade. Para atender a critérios sustentáveis, é necessário que a universidade internalize e viva estes critérios. Este processo não é linear e não é instantâneo.

Infere-se que as campanhas de conscientização da instituição, apesar dos avanços nos últimos anos, ainda são tímidas e demandam maior engajamento da comunidade acadêmica.

Como limitações deste estudo, pode-se apontar a dificuldade de conciliação de horários com os sujeitos da pesquisa para coleta de dados e o fato de nem todos os informantes possuírem o perfil de falar demoradamente sobre o tema objeto da pesquisa.

Recomenda-se que, em pesquisas futuras, seja analisada a aprendizagem como foco na sugestão de um modelo de processo de aprendizagem organizacional para a Universidade Federal de Santa Catarina.

\section{REFERENCIAS}

ADOMßENT, M.; FISCHER, D.; GODEMANN, J.; HERZIG, C.; OTTE, I.; RIECKMANN, M.; TIMM, J. Emerging areas in research on higher education for sustainable development $\mathrm{e}$ management education, sustainable consumption and perspectives from Central and Eastern Europe. Journal of Cleaner Production, Elsevier Ltd., n. 62, p. 1-7, 2014.

AMARAL, L. P.; MARTINS, N.; GOUVEIA, J. B. Quest for a Sustainable University: a review. International Journal of Sustainability in Higher Education, v. 16, n. 2, p. 155$172,2015$.

ARGYRIS, Chris; SCHÖN, Donald. Organizational Learning: a Theory of Action Perspective. Reading-Mass: Addison-Wesley, 1978.

BARTH, Matthias; ADOMßENT, Maik; FISCHER, Daniel; RICHTER, Sonja; RIECKMANN, Marco. Learning to change universities from within: a service-learning perspective on promoting sustainable consumption in higher education. Journal of Cleaner Production, n. 62, Elsevier Ltd., p. 72-81, 2014.

BATESON, G. Steps to an Ecology of Mind. New York: Ballantine, 1981.

BIDERMAN, Rachel; MACEDO, Laura Silvia Valente de; MONZONI, Mário; MAZON, Rubens. Guia de Compras Públicas Sustentáveis- Fundação Getúlio Vargas e ICLEI. Rio de Janeiro: Editora FGV, 2006.

BONI, V.; QUARESMA, S. J. Aprendendo a entrevistar: como fazer entrevistas em Ciências Sociais. Revista Eletrônica dos Pós-Graduandos em Sociologia Política da UFSC, Vol. 2 no 1 (3), janeiro-julho/2005, p. 68-80.

CASTILHO, N. T.; SILVA, CES; TURRIONI, J. B. Aprendizagem organizacional e gestão do conhecimento. Anais do Simpósio de Engenharia de Produção (SIMPEP). Bauru, São Paulo, Brasil, 2004.

CHADWICK, Ingrid C.; RAVER, Jana L. Motivating Organizations to Learn Goal Orientation and Its Influence on Organizational Learning. Journal of Management, v. 41, n. 3, p. 957-986, 2015.

CRESWELL, J. W. Projeto de pesquisa: Métodos qualitativo, quantitativo e misto. Porto Alegre: Artmed, 2010. p. 177-205.

DICLE, U. KOSE, C. The impact of organizational learning on corporate sustainability and strategy formulation with the moderating effect of industry type.10th International Strategic 
Management Conference. Procedia - Social and Behavioral Sciences, n. 150, p. 958 - 967, 2014.

EASTERBY-SMITH, M. Disciplines of Organizational Learning: Contributions and Critiques. Human Relations, v. 50, n. 9, p. 1085-113, 1997.

GODEMANN, J.; HAERTLE, J.; HERZIG, C.; MOON, J. United Nations supported Principles for Responsible Management Education: purpose, progress and prospects. Journal of Cleaner Production, Elsevier Ltd., n. 62, p.16-23, 2014.

HESSELBARTH, C.; SCHALTEGGER, S. Educating change agents for sustainability learnings from the first sustainability management master of business administration. Lüneburg, Germany. Journal of Cleaner Production, n. 62, p. 24-36, 2014.

HULT, G. T. M. Managing the international strategic sourcing process as a market- driven organizational learning system. Decision Sciences, v. 29, n. 1, p. 193-216, 1998.

KOO, Yunmo et al. Effect of multi-vendor outsourcing on organizational learning: A social relation perspective. Information \& Management, 2016.

LAKATOS, E. M. \& MARCONI, M. de A. Técnicas de Pesquisa. $3^{\text {a }}$ ed. São Paulo: Editora Atlas, 1996.

LEAL FILHO, W. About the role of universities and their contribution to sustainable development. Higher Education Policy, v. 24, p. 427-438, 2011.

LIN, H. F. Empirically testing innovation characteristics and organizational learning capabilities in e-business implementation success. Internet Research, v. 18, n. 1, 6078.2008.

MALINOWSKI, Bronislaw. Argonauts of the Western Pacific. Prospect Highs: Waveland Press, 1984.

MARQUARDT, M. Building the learning organization. Davis: Black Publishing, v. 19, n. 5, p. 182-184, 2002.

MOORE, J. Seven recommendations for creating sustainability education at the university level: A guide for change agents. International Journal of Sustainability in Higher Education, v. 6, n. 4, p. 326-339, 2005.

NICOLAIDES, A. The implementation of environmental management towards sustainable universities and education for sustainable development as an ethical imperative. International Journal of Sustainability in Higher Education, v. 7, n. 4, p. 414-424, 2006. OECD - Organization for Economic Co-Operation and Development, 2008. Promoting Sustainable Consumption. Good Practices in OECD Countries. Disponível em: http://www.oecd.org/dataoecd/1/59/40317373.pdf. Paris. Acesso em: 25 mai. 2016.

PORTER, M. E.; KRAMER, M. R. Creating Shared Value. Harvard Business Review; Jan/Feb 2011, Vol. 89 Issue 1/2, p 62-77, 5, 2011.

PROBST, Gilbert. BUCHEL, Bettina S.T. Organizational Learning. London: Prentice Hall, 1997.

RICHARDS, D. J.; GLADWIN, T. N. Sustainability metrics for the business enterprise. Environmental Quality Management, v. 8, n. 3, p. 11-21, 1999.

SANDHU, S. Shifting paradigms in corporate environmentalism: From poachers to gamekeepers. Business and Society.Review, v. 115, n. 3, p. 285-310, 2010.

SENGE, P. M. The fifth discipline: The art and practice of learning organization. New York Doubleday, 1990.

SILVEIRA, M. A.; KIKUCHI, L. S.; POLICENO, C. A. Inovação e Aprendizagem Organizacional para a Sustentabilidade: Desenvolvimento de Competências na Indústria de Equipamentos Eletrodomésticos. Gestão \& Conexões = Management and Connections Journal, Vitória (ES), v. 2, n. 1, p. 76-93, jan./jun. 2013. 
SHRIBERG, M. Toward sustainable management: The University of Michigan Housing Division's approach. Journal of Cleaner Production, v. 10, n. 1, p. 41-45, 2002.ISSN 09596526.

TAYLOR, S.; BOGDAN, R. Introduction to qualitative research methods: a guidebook and resource. $3^{\mathrm{a}}$ ed. USA: John Wiley \& Sons Inc., 1998.

THOMPSON, R., GREEN, W., When sustainability is not a priority. International Journal of Sustainability in Higher Education, v. 6, n. 1, p. 7-17. 2005.

UNIVERSIDADE FEDERAL DE SANTA CATARINA (UFSC). Coletânea de Melhores Práticas de Gestão do Gasto Público. Disponível em: $<$ http://pls.ufsc.br/files/2013/02/Manual-de-Boas-Praticas-do-Servico-Publico.pdf $>$ Acesso em: 20 mai. 2016.

UNIVERSIDADE FEDERAL DE SANTA CATARINA (UFSC). Plano de Desenvolvimento Institucional 2010-2014. Universidade Federal de Santa Catarina. Florianópolis, p. 110. 2010.

VELAZQUEZ, L., MUNGUIA, N., PLATT, A., TADDEI, J., Sustainable university: what can be the matter? Journal of Cleaner Production, v. 14, p. 810-819, 2006.

WALS, Arjen. E. J. Sustainability in higher education in the context of the UN DESD: a review of learning and institutionalization processes. Journal of Cleaner Production, Elsevier Ltd., n. 62, p. 8-15, 2014.

WEICK, K.; WESTLEY, F. Organizational Learning: affirming an oxymoron. In: CLEGG, S.; HARDY, C.; NORD, W. Handbook of Organization Studies. London: Sage, 1996. p. 440-458.

ZHANG, N.; WILLIAMS, I.D.; KEMP, S.; SMITH.; N.F. Greening academia: Developing sustainable waste management at Higher Education Institutions. Waste Management, n. 31, p. 1606-1616, 2011. 